Pacific Journal of 


\title{
SPLITTING RING OF A MONIC SEPARABLE POLYNOMIAL
}

\section{Stuart Sui-Sheng Wang}

\begin{abstract}
In this short note we prove that if $S=R[x]=R[X] /\langle f(X)\rangle$ is separable over $R$, where $f(X)$ is a monic polynomial over $R$, then the embedding set up by Auslander and Goldman is the same as the splitting ring of $f$ over $R$ constructed by Barnard.
\end{abstract}

Throughout, the terms "ring", "algebra", and "ring homomorphism" are to be interpreted as in the category of commutative rings with identity. $S$ is an algebra over the ring $R, f(X)$ is a monic polynomial of degree $n$ over $R, d_{f}$ is the discriminant of $f, Z_{i}, W_{i}(1 \leqq i \leqq n)$ are indeterminates over $R, G$ is the symmetric group on $n$ symbols, and $\epsilon(\sigma)$ is the signature of the permutation $\sigma$.

Auslander and Goldman [1, Theorem A.7, p. 399] show that if $S$ is separable over $R$ such that $S$ is free of rank $n$ as a module over $R$, then $S$ can be embedded into a Galois extension $\Omega$ of $R$ with group $G$. Their $\Omega$ is defined as follows: Let $\Gamma=\bigotimes^{n} S$ denote the $n$-fold tensor product of $S$ over $R, E=\wedge^{n} S$ denote the $n$-th exterior power of $S$ over $R, \pi: \otimes^{n} S \rightarrow \wedge^{n} S$ be the natural ( $R$-module) homomorphism, $I$ be the $R$-module conductor $(\operatorname{ker} \pi)$ : $\left(\otimes^{n} S\right)$, (so $I$ is an ideal of $\otimes^{n} S$ and is also an $R$-submodule of ker $\pi)$, and define $\Omega=\left(\otimes^{n} S\right) / I$. The group $G$ acts on $\otimes^{n} S$ by permuting the $n$ factors. Since $\pi \sigma(\xi)=\epsilon(\sigma) \pi(\xi)$ for $\xi \in \otimes^{n} S$ and $\sigma \in G, \operatorname{ker} \pi$ is stable under the action of $G$, hence so is I. Thus $G$ acts on $\Omega$. Since $\wedge^{n} S \approx \bigotimes^{n} S / \operatorname{ker} \pi$ is a free $R$-module (of rank 1), $R \cap \operatorname{ker} \pi=0$, so that $R \cap I=0$, and thus the restriction of the $\operatorname{map} \Gamma \rightarrow \Omega=\Gamma / I$ to $R$ is injective, i.e., $\Omega$ contains $R$. For $1 \leq i \leqq n$, let $p_{i}: S \rightarrow \otimes^{n} S$ be the $R$-algebra homomorphism defined by $p_{i}(s)=$ $1 \otimes \cdots \otimes 1 \otimes s \otimes 1 \otimes \cdots \otimes 1$ (the $s$ occurring in the $i$-th place). Then it follows from the properties of the exterior algebra that for all $s \in S$,

$$
p_{1}(s)+\cdots+p_{n}(s)-\operatorname{trace}_{s / R}(\bar{s}) \in I
$$

where $\bar{s}$ denotes the $R$-endomorphism of $S$ defined by multiplication by $s$. Assume furthermore $S$ is separable over $R$, then $t=\operatorname{trace}_{s / R}$ is nondegenerate ([1, Proposition A.4, p. 397]). It follows from (*) and the non-degeneracy of $t$ that the composite of the $R$-algebra homomorphisms $S \stackrel{\longrightarrow}{\longrightarrow} \boldsymbol{\longrightarrow}$ gives an imbedding of $S$ as an $R$-algebra into $\Omega$. Then it can be shown that $\Omega$ is a Galois extension of $R$ with group $G$ ([1, line 14 of p. 400 to line 18 of p. 402]). 
On the other hand, Barnard [2, §5, pp. 285-289] constructs a splitting ring $R_{f}$ for a monic polynomial $f(X)=X^{n}+a_{n-1} X^{n-1}+\cdots+a_{0}$ of degree $n$ over $R$. More specifically,

$$
\begin{aligned}
R_{f} & =R\left[z_{1}, \cdots, z_{n}\right] \\
& =R\left[Z_{n}, \cdots, Z_{n}\right] /\left\langle e_{1}+a_{n-1}, e_{2}-a_{n-2}, \cdots, e_{n}+(-1)^{n-1} a_{0}\right\rangle
\end{aligned}
$$

where $e_{i}(1 \leqq i \leqq n)$ is the elementary symmetric polynomial of degree $i$ in the indeterminates $Z_{1}, \cdots, Z_{n}$. The ring $R_{f}$ is characterized by the following universal property: the polynomial $f$ factors into the product of $n$ linear factors over $R_{f}, f(X)=\Pi_{i=1}^{n}\left(X-z_{i}\right)$. And if $A$ is an $R$-algebra over which $f$ factors into the product of $n$ linear factors, $f(X)=$ $\Pi_{i=1}^{n}\left(X-a_{i}\right)$, then there is an $R$-algebra homomorphism $R_{f} \rightarrow A$ which maps $z_{i}$ to $a_{i}$ for $i=1, \cdots, n$. As usual, such an $R_{f}$ is unique up to isomorphism. The ring $R_{f}$ contains $R$, is a free $R$-module of rank $n$ ! and $G$ acts on $R_{f}$ by permuting the $z_{i}$ 's. Moreover, $R_{f}$ contains $R[x]=R[X] /\langle f(X)\rangle$ as an $R$-subalgebra. It is also shown that $R_{f}$ is a Galois extension of $R$ with group $G$ if and only if $\Pi_{i \neq j}\left(z_{i}-z_{j}\right)$ is a unit in $R$.

However, a moment's reflection will convince one that $\Pi_{i \neq j}\left(z_{i}-z_{j}\right)$ is $d_{f}$ up to a sign. Recall $d_{f}$, the discriminant of $f$, is defined to be the discriminant of the basis $1, x, \cdots, x^{n-1}$ of $R[x]$ with respect to $R$, i.e., the determinant of the $n \times n$ matrix $\left(\operatorname{trace} e_{R[x] / R}\left(x^{i-1} x^{j-1}\right)\right) 1 \leqq i \leqq n 1 \leqq j \leqq n$.

For the remainder of the note, $S$ will be $R[x]=R[X] /\langle f(X)\rangle$ and will be assumed to be separable over $R$ or equivalently [5] $d_{f}$ is a unit in $R$.

We will show that there is a $\varphi: \Omega \rightarrow R_{f}$ which is both an $R$-algebra and a $G$-module homomorphism. To establish this, let us first observe that there is an $R$-algebra isomorphism

$$
\bigotimes^{n} S \approx R\left[W_{1}, \cdots, W_{n}\right] /\left\langle f\left(W_{1}\right), \cdots, f\left(W_{n}\right)\right\rangle
$$

where for $g(x) \in S=R[x], p_{i}(g(x))$ goes to the coset of $g\left(W_{i}\right)$ $(1 \leqq i \leqq n)$. Here $p_{i}$, as before, denotes the $i$ th injection: $S \rightarrow \otimes^{n} S$. On the other hand, there is another description of $I$. Put $x_{i}=x^{i-1}, t=$ trace $_{S / R}$, and let the $n \times n$ matrix $\left(\lambda_{i j}\right)$ be the adjoint matrix of $\left(t\left(x_{i} x_{j}\right)\right)$; let

$$
y_{\jmath}=\left(\lambda_{j 1} x_{1}+\lambda_{j 2} x_{2}+\cdots+\lambda_{j n} x_{n}\right) d_{f}^{-1} \quad(1 \leqq j \leqq n) .
$$

Then $t\left(x_{i} y_{j}\right)=\delta_{i j}(1 \leqq i, j \leqq n)$ [5]. By $\alpha(\xi)$ will be meant the (contravariant) skew-symmetrization of $\xi$, i.e., $\alpha(\xi)=\Sigma_{\sigma \in G} \epsilon(\sigma) \sigma(\xi)$ if $\xi \in \otimes^{n} S$. Then $I$ is precisely the principal ideal generated by 
$\alpha\left(x_{1} \otimes \cdots \otimes x_{n}\right) \alpha\left(y_{1} \otimes \cdots \otimes y_{n}\right)-1 \otimes \cdots \otimes 1 \quad[1, \quad$ p. $\quad 401] . \quad$ Let $s_{1}, \cdots, s_{n} \in S$; then $\alpha\left(s_{1} \otimes \cdots \otimes s_{n}\right)=\operatorname{det}\left(p_{i}\left(s_{j}\right)\right)$. This may be verified by expanding as an alternating sum of $n$ ! terms; these terms are precisely those in the sum $\Sigma_{\sigma \in G} \epsilon(\sigma) \sigma\left(s_{1} \otimes \cdots \otimes s_{n}\right)$ [1, p. 401]. Accordingly $\alpha\left(x_{1} \otimes \cdots \otimes x_{n}\right)=\operatorname{det}\left(p_{i}\left(x_{j}\right)\right) \quad$ and $\quad \alpha\left(y_{1} \otimes \cdots \otimes y_{n}\right)=\operatorname{det}\left(p_{i}\left(y_{j}\right)\right)=$ $d_{f}^{-1} \operatorname{det}\left(p_{i}\left(x_{j}\right)\right)$ by taking $\operatorname{det}\left(\lambda_{i j}\right)=d_{f}^{n-1}$ into account. Hence $I$ is the principal ideal generated by $\left(\operatorname{det}\left(p_{i}\left(x_{j}\right)\right)\right)^{2}-d_{f}$. If follows that the image of $I$ in $R\left[W_{1}, \cdots, W_{n}\right]$, under the aforementioned isomorphism $\otimes^{n} S \approx$ $R\left[W_{1}, \cdots, W_{n}\right] /\left\langle f\left(W_{1}\right), \cdots, f\left(W_{n}\right)\right\rangle$, is the principal ideal generated by $\left[\operatorname{det}\left(W_{l}^{\prime-1}\right)\right]^{2}-d_{f}$. Note, however, it is well-known that $\operatorname{det}\left(W_{i}^{j-1}\right)$, a so-called Vandermonde determinant of the sequence $\left(W_{1}, \cdots, W_{n}\right)$, has the value $\Pi_{i>j}\left(W_{i}-W_{j}\right)$. Consequently, this map induces an isomorphism

$$
\Omega \approx R\left[W_{1}, \cdots, W_{n}\right] /\left\langle f\left(W_{1}\right), \cdots, f\left(W_{n}\right), d_{f}-\left(\prod_{i>j}\left(W_{1}-W_{j}\right)\right)^{2}\right\rangle
$$

and therefore, since $f\left(z_{1}\right)=0, \cdots, f\left(z_{n}\right)=0, d_{f}=\left(\Pi_{i>j}\left(z_{i}-z_{j}\right)\right)^{2}$, there is an $R$-algebra homomorphism $\varphi: \Omega \rightarrow R_{f}$ which takes the coset of $W_{i}$ to $z_{\imath} \quad(1 \leqq i \leqq n)$. Obviously such an $\varphi$ preserves the $G$ action. Therefore $\Omega \approx R_{f}$ by [3, Theorem 3.4, p.12]. This establishes our assertion.

REMARKs. (1) As a matter of fact, we have also proved the following proposition: If $S$ is separable over $R$, then the surjective $R$-algebra homomorphism from $R\left[w_{1}, \cdots, w_{n}\right]=$ $R\left[W_{1}, \cdots, W_{n}\right] /\left\langle f\left(W_{1}\right), \cdots f\left(W_{n}\right), \quad d_{f}-\left(\Pi_{i>1}\left(W_{l}-W_{j}\right)\right)^{2}\right\rangle \quad$ to $R_{f}=$ $R\left[z_{1}, \cdots, z_{n}\right]$ is an isomorphism. This is not necessarily true if $S$ is not separable over $R$. For example, take $R$ to be the field of real numbers and $f(X)=X^{2}+2 X+1$, then $R\left[W_{1}, W_{2}\right] /\left\langle f\left(W_{1}\right), f\left(W_{2}\right),\left(W_{2}-W_{1}\right)^{2}\right\rangle$ has dimension 3 over $R$ while $R_{f}$ has dimension 2 over $R$.

(2) Recently, Andy Magid has pointed out that the splitting ring constructed by Barnard is the same as the "free splitting ring" constructed by Nagahara in [4, pp. 150-152].

\section{REFERENCES}

1. M. Auslander and O. Goldman, The Brauer group of a commutative ring, Trans. Amer. Math. Soc., 97 (1960), 367-409.

2. A. D. Barnard, Commutative rings with operators (Galois theory and ramification), Proc. London Math. Soc., (3) 28 (1974), 274-290.

3. S. U. Chase, D. K. Harrison and A. Rosenberg, Galois theory and Galois cohomology of commutative rings, Mem. Amer. Math. Soc., No. 52 (1965) (third printing 1969), 1-19. 
4. T. Nagahara, On separable polynomials over a commutative ring II, Math. J. of Okayama Univ., 15 (1971/72), 149-162.

5. S. S. Wang, Separable algebras and free cubic extensions over commutative rings, Ph.D. thesis, Cornell University, 1975.

Received April 28, 1976 and in revised form June 10, 1977.

UNIVERSITY OF OKLAHOMA

NORMAN, OK 73069

Current address: DePARTMENT OF MATHEMATICS

TEXAS TECH UNIVERSITY

LUBBOCK, TX 79409 


\section{PACIFIC JOURNAL OF MATHEMATICS EDITORS}

ICHARD ARENS (Managing Editor)

niversity of California

os Angeles, CA 90024

\section{. A. BEAUmont}

niversity of Washington

sattle, WA 98105

. C. MOORE

niversity of California

erkeley, CA 94720
J. DUGUNDJI

Department of Mathematics

University of Southern California

Los Angeles, CA 90007

R. FINN AND J. MiLgRAM

Stanford University

Stanford, CA 94305

\section{ASSOCIATE EDITORS}
F. BECKENBACH
B. H. NEUMANN
F. WOLF
K. YosHidA

\section{SUPPORTING INSTITUTIONS}

NIVERSITY OF BRITISH COLUMBIA

UNIVERSITY OF SOUTHERN CALIFORNIA

ALIFORNIA INSTITUTE OF TECHNOLOGY STANFORD UNIVERSITY

NIVERSITY OF CALIFORNIA

ONTANA STATE UNIVERSITY

UNIVERSITY OF HAWAII

NIVERSITY OF NEVADA

UNIVERSITY OF TOKYO

EW MEXICO STATE UNIVERSITY

UNIVERSITY OF UTAH

REGON STATE UNIVERSITY

NIVERSITY OF OREGON

WASHINGTON STATE UNIVERSITY

UNIVERSITY OF WASHINGTON

SAKA UNIVERSITY

AMERICAN MATHEMATICAL SOCIETY

The Supporting Institutions listed above contribute to the cost of publication of this Journal, but they a t owners or publishers and have no responsibility for its contents or policies.

Mathematical papers intended for publication in the Pacific Journal of Mathematics should be in typ Irm or offset-reproduced (not dittoed), double spaced with large margins. Underline Greek letters in re ierman in green, and script in blue. The first paragraph or two must be capable of being used separately as 'nopsis of the entire paper. Items of the bibliography should not be cited there unless absolutely necessary, hich case they must be identified by author and Journal, rather than by item number. Manuscripts, uplicate, may be sent to any one of the four editors. Please classify according to the scheme of Math. Revieu Idex to Vol. 39. All other communications should be addressed to the managing editor, or Elaine Bart Iniversity of California, Los Angeles, California, 90024.

100 reprints are provided free for each article, only if page charges have been substantially pai dditional copies may be obtained at cost in multiples of 50 .

The Pacific Journal of Mathematics is issued monthly as of January 1966. Regular subscription rate: \$72. year (6 Vols., 12 issues). Special rate: $\$ 36.00$ a year to individual members of supporting institutions.

Subscriptions, orders for numbers issued in the last three calendar years, and changes of address should ent to Pacific Journal of Mathematics, 103 Highland Boulevard, Berkeley, California, 94708.

UBLISHED BY PACIFIC JOURNAL OF MATHEMATICS, A NON-PROFIT CORPORATION

Printed at Jerusalem Academic Press, POB 2390, Jerusalem, Israel.

Copyright (C) 1978 Pacific Journal of Mathematics

All Rights Reserved 


\section{Pacific Journal of Mathematics}

\section{Vol. 75, No. $1 \quad$ September, 1978}

Mieczyslaw Altman, General solvability theorems

Denise Amar and Eric Amar, Sur les suites d'interpolation en plusieurs variables ..........................................

Herbert Stanley Bear, Jr. and Gerald Norman Hile, Algebras which satisfy a second order linear partial differential equation ..................

Marilyn Breen, Sets in $R^{d}$ having $(d-2)$-dimensional kernels ............

Gavin Brown and William Moran, Analytic discs in the maximal ideal space

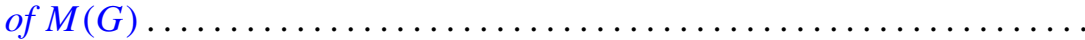

Ronald P. Brown, Quadratic forms with prescribed Stiefel-Whitney

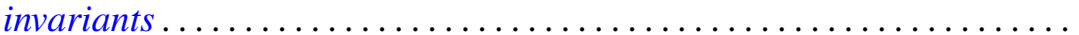

Gulbank D. Chakerian and H. Groemer, On coverings of Euclidean space by convex sets

S. Feigelstock and Z. Schlussel, Principal ideal and Noetherian groups.....

Ralph S. Freese and James Bryant Nation, Projective lattices ............

Harry Gingold, Uniqueness of linear boundary value problems for

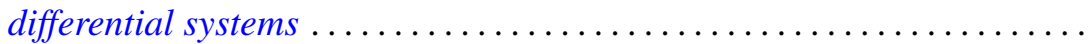

John R. Hedstrom and Evan Green Houston, Jr., Pseudo-valuation domains. . .

William Josephson, Coallocation between lattices with applications to measure extensions

M. Koskela, A characterization of non-negative matrix operators on $l^{p}$ to $l^{q}$ with $\infty>p \geq q>1$

Kurt Kreith and Charles Andrew Swanson, Conjugate points for nonlinear differential equations...........................

Shoji Kyuno, On prime gamma rings ........................ 185

Alois Andreas Lechicki, On bounded and subcontinuous multifunctions ..

Roberto Longo, A simple proof of the existence of modular automorphisms in approximately finite-dimensional von Neumann algebras ...

Kenneth Millett, Obstructions to pseudoisotopy implying isotopy for

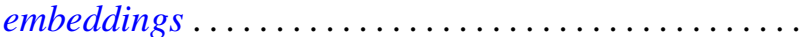

William F. Moss and John Piepenbrink, Positive solutions of elliptic equations. .

Mitsuru Nakai and Leo Sario, Duffin's function and Hadamard's

conjecture

Mohan S. Putcha, Word equations in some geometric semigroups ...

Walter Rudin, Peak-interpolation sets of class $C^{1} \ldots \ldots \ldots$

Elias Saab, On the Radon-Nikodým property in a class of locally convex

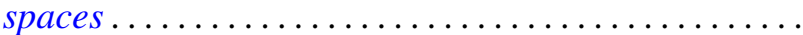

